BULLETIN Bulletin hispanique

HISPANIQUE Université Michel de Montaigne Bordeaux

122-1 $\mid 2020$

Variations donjuanesques

\title{
Nuestro futuro está en el aire. Aviones en la literatura española (Hasta 1936)
}

Sevilla, Renacimiento, 2020

Francisco Javier Díez de Revenga

\section{CpenEdition}

\section{Journals}

Edición electrónica

URL: http://journals.openedition.org/bulletinhispanique/11031

DOI: 10.4000/bulletinhispanique.11031

ISSN: 1775-3821

\section{Editor}

Presses universitaires de Bordeaux

\section{Edición impresa}

Fecha de publicación: 18 junio 2020

Paginación: 371-374

ISBN: 979-10-300-0592-9

ISSN: 0007-4640

\section{Referencia electrónica}

Francisco Javier Díez de Revenga, «Nuestro futuro está en el aire. Aviones en la literatura española (Hasta 1936)», Bulletin hispanique [En línea], 122-1 | 2020, Publicado el 18 junio 2020, consultado el 26 enero 2021. URL: http://journals.openedition.org/bulletinhispanique/11031 ; DOI: https://doi.org/10.4000/ bulletinhispanique.11031

Este documento fue generado automáticamente el 26 enero 2021

Tous droits réservés 


\section{Nuestro futuro está en el aire. Aviones en la literatura española (Hasta 1936)}

Sevilla, Renacimiento, 2020

Francisco Javier Díez de Revenga

\section{REFERENCIA}

Nuestro futuro está en el aire. Aviones en la literatura española (Hasta 1936), edición, estudio y antología de Rafael ALARCÓN SIERRA, Sevilla, Renacimiento, 2020, 398 págs. (Los Cuatro Vientos, 155), ISBN: 978-84-17950-44-6.

1 La relación de la literatura con la aviación es campo bastante poco explorado entre los estudiosos de la literatura española, y lo cierto es que, especialmente en las primeras décadas de siglo XX, dio mucho que hablar y que escribir, y fueron numerosos los escritores españoles que mostraron en su obra el asombro que producía el gran invento y la gran revolución social que supuso la aviación, sobre todo en aquellos primeros años. Una importante huella dejó la aviación en la literatura española de los años veinte y treinta del siglo pasado, y este libro de Rafael Alarcón Sierra lo demuestra claramente. Porque en sus páginas lleva a cabo una completa recopilación de textos en prosa, de un buen número de escritores de la literatura española sobre la aviación hasta el año 1936. Ha precedido la antología de un amplio y documentado estudio preliminar. Seguirá otro volumen, aún más apasionante sin duda, sobre la aviación en la poesía española, en esas mismas décadas.

2 Parafrasea Rafael Alarcón Sierra en el título de este ensayo un eslogan que Picasso introdujo en tres lienzos pintados en 1912, «Notre avenir est dans l'air», con su significado ambivalente. Y lo que ha pretendido es, sobre todo, mostrar la labor de escritores consagrados en relación con la aviación y su representación en su literatura, en sus ensayos, en sus artículos y crónicas, y en sus novelas, porque la prensa de la época está bien nutrida de otras numerosas representaciones del fenómeno que tanto interesaba y asombraba a los lectores. 
3 Sobre la fecha final de la selección, 1936, la justifica Alarcón porque durante la Guerra de España y, sobre todo, durante la Segunda Guerra Mundial, la aviación perdió su inocencia y se convirtió en otra cosa muy diferente: «si en la Gran Guerra los pilotos eran todavía los caballeros del aire, en la Guerra Civil española y en la Segunda Guerra Mundial se mudaron en implacables embajadores de la muerte con sus bombardeos sobre la población civil (de Guernica a Dresde) llegando al horror absoluto del lanzamiento de la bomba atómica». Y ese es el encanto de las páginas que ha escogido Alarcón Sierra, que están presididas por el asombro y la perplejidad ante la aviación, por el gozo de lo excitante de los primeros vuelos y sobre todo por las experiencias reflejadas en la literatura de este buen sector de escritores selectos y escogidos.

Organiza el estudio que precede a la antología en varios capítulos, y, tras una referencia a los vuelos imaginarios, se detiene en los vuelos reales, los realizados desde finales del siglo XVIII y durante el siglo XIX en globos aerostáticos, para enseguida pasar a los vuelos reales ya en planeadores y primeros prototipos, advirtiendo que pronto el avión se ha de convertir en un apasionante signo de modernidad, que fue adoptado por el futurismo como un auténtico emblema.

La edad de oro de la aviación estará representada en los artículos y textos seleccionados de Jacinto Miquelarena, Corpus Barga, Enrique Jardiel Poncela y César González-Ruano. Seguirán en el análisis del editor las primeras novelas sobre la aviación, que tienen como héroes a los primeros pioneros de la aviación. Francisco Cambia y Concha Espina serán los primeros en crear narraciones con la aviación como asunto central de sus novelas, y en el caso de Espina se destaca que posiblemente fuera la primera escritora española que realizase un vuelo (en 1916) en un monoplano, cuyas experiencias utilizó para su novela corta Talín.

6 Dedica un espacio detenido en su estudio al intermedio bélico que supuso la Gran Guerra. Aunque España permaneció neutral, son varios los escritores que fueron enviados a los distintos frentes, entre ellos Valle-Inclán y Azorín, que junto a Ricardo León y Agustí Calvet (Gaziel) reflejaron en sus textos la importancia de la aviación en los distintos frentes de la guerra. Y serán ya las décadas de los veinte y de los treinta las que den entrada plenamente a la aviación en el campo de la novela, por lo que dedica todo un apartado al avión en la narrativa de vanguardia. Finalmente, un capítulo dedicado a los escritores también vuelan muestra cómo otro importante grupo de autores reflejan sus experiencias tras haber realizado diversos vuelos.

7 La antología es espléndida porque permite al lector disponer de los textos y poder leerlos directamente para formarse una idea clara de lo que supone la presencia de la aviación en la literatura española de aquellos años. Así, el apartado dedicado a la importancia de la aviación recoge esta interesante selección de artículos, crónicas y reportajes: Jacinto Miquelarena, «Principios de siglo», Stadium (Notas de sport); Corpus Barga, La audacia del vuelo; Enrique Jardiel Poncela, La travesía atlántica del conde Zeppelin; Jacinto Miquelarena, "Schreiber, el "Clandestino" (Reportaje)» y Veintitrés; y César González-Ruano, La hazaña del «Dornier 16». Son textos escritos entre 1910 y 1934, y responden a lo que para ellos significó la aviación en su edad de oro.

8 En la sección dedicada a la narrativa y las primeras novelas se recogen textos de Francisco Camba, Los nietos de Ícaro. Novela, y de Concha Espina, Talín. Fueron los primeros que trataron en sus novelas a los pioneros del aire, y en el caso de Cambia, en fecha tan temprana como 1911. La de Concha Espina es de 1918. 
El intermedio bélico, el avión en la gran guerra, está representado por: Gaziel (Agustín Calvet), Diario de un estudiante. París 1914 y El año de Verdún; Ramón del Valle-Inclán, La media noche. Visión estelar de un momento de guerra, y En la luz del día. Visión estelar de un momento de guerra; Ricardo León, Europa trágica; y Azorín, París, bombardeado. Todos ellos, en sus crónicas de guerra, reflejaron la importancia de los aeroplanos en el campo de batalla y las gestas heroicas de algunos de ellos. Las fechas se corresponden con las de la Gran Guerra, entre 1914 y 1918.

La narrativa en las vanguardias y más allá recupera escritos de: Ramón Gómez de la Serna, Greguerías y Policéfalo y señora. Novela; Ramón Acín, Las corridas de toros en 1970. Estudios para una película cómica; Juan Chabás, Puerto de sombra. Novela; Antonio Espina, Luna de copas; Felipe Ximénez Sandoval, Tres mujeres más Equis. Novela lírica; y José María Pemán, De Madrid a Oviedo, pasando por las Azores. Sus fechas van desde 1923 a 1933.

11 Y, finalmente, el apartado dedicado a los escritores también vuelan, crónicas y libros de viaje, recoge textos que reflejan las impresiones de sus primeros vuelos: Corpus Barga, París-Madrid. Un viaje en el año 19; Julio Camba, Sobre la emoción del primer vuelo, Sobre esta emoción y la emoción artística, Sobre el peligro real y el peligro imaginario; Luis de Oteyza, Al Senegal en avión. Reportaje aéreo; César González-Ruano, Un español en Portugal; Manuel Chabes Nogales, La vuelta a Europa en avión; Jacinto Miquelarena, «Por la ruta del cielo...», El gusto de Holanda; Ernesto Giménez Caballero, «Sobre el signo avión», Julepe de Menta; y Ramón J. Sender, Casas Viejas. Las fechas de estos textos van desde 1920 a 1933.

En su estudio preliminar, Rafael Alarcón Sierra realiza un detenido análisis de cada uno de los textos que incluye en la antología y documenta pormenorizadamente el significado de todos ellos, así como la valoración que merecen como reflejo de la pasión por la aviación en aquellos años. Las circunstancias históricas que rodean a cada uno de los textos antologados son explicadas y analizadas por el editor para justificar su sentido y también la trascendencia que pudo tener en su época, y puede representar ahora, para el conjunto de la historia literaria española de aquellos años tan fecundos y míticos.

Justamente uno de los aspectos más reveladores es la significativa personalidad de gran parte de los escritores escogidos, por lo que en el caso de los más renombrados y significativos esta antología supone también una aportación complementaria a lo que supone su obra y su significación en la literatura española del siglo XX como puede ser el caso de Valle-Inclán, Azorín, Ramón Gómez de la Serna, Concha Espina o Ramón J. Sender por solo recordar a los más señalados.

\section{AUTORES}

FRANCISCO JAVIER DÍEZ DE REVENGA

Universidad de Murcia 